\title{
Anetoderma of Jadassohn
}

\begin{tabular}{|l|l|l} 
S.V. & Van & Brabandt
\end{tabular}

A 16-year-old boy exhibited skin lesions on his neck, chest and arms. They consisted of small, oval, pink to red papules, $0.3-0.5 \mathrm{~cm}$ in diameter, evolving to wrinkled, atrophic patches of about $6 \mathrm{~mm}$ in diameter with occasionally a blueish colour (fig. 5). The centre of the lesions was less resistant to pressure than the surrounding ring of normal skin. Histolog-ically, there was no elastine in the dermis. The serology for syphilis was negative.

Case Presentations

\section{4}

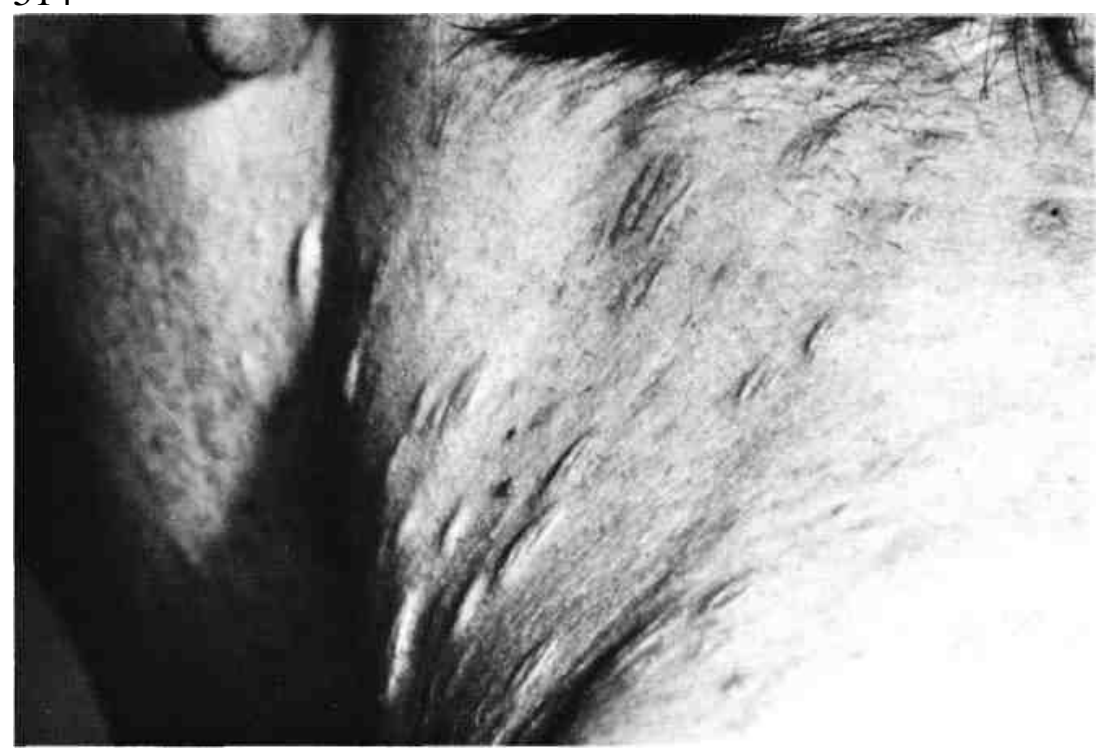

Fig. 5. Anetoderma, Jadassohn type.

Calcinosis circumscripta

S. Van Brabandt

A 9-year-old girl has solid intra- and subcutaneous tumors on her scalp and fingers since her birth. Recently, similar lesions have also appeared on the dorsal aspect of her toes and elbows. Some of the lesions ulcerated (fig. 6). X-rays of the hands and feet disclosed soft-tissue calcifications. In addition to the skin lesions there were corneal calcifications and chalk-white plaques on the ear drums. On histopathological examination of a tumour of the thumb, intradermal calcium deposits surrounded by an inflammatory reaction of the foreign-body granu-loma type were found in the dermis.

No metabolic disorder could be detected. 